\title{
Blood serum levels of E-cadherin in patients with colorectal cancer
}

\author{
Dariusz Cepowicz' Konrad Zaręba $^{1}$, Anna Pryczynicz² Tomasz Dawidziuk $^{1}$, Joanna Żurawska ${ }^{3}$, \\ Joanna Hołody-Zaręba ${ }^{4}$, Mariusz Gryko' ${ }^{1}$, Bogusław Kędra ${ }^{1}$ \\ ${ }^{1} 2^{\text {nd }}$ Department of General and Gastroenterological Surgery, Medical University of Bialystok, Bialystok, Poland
${ }^{2}$ Department of Pathomorphology, Medical University of Bialystok, Bialystok, Poland
${ }^{3}$ Department of Clinical Molecular Biology, Medical University of Bialystok, Bialystok, Poland
${ }^{4}$ Department of Gynaecology and Obstetrics, J. Śniadecki Memorial Voivodeship Hospital, Bialystok, Poland
}

Gastroenterology Rev 2017; 12 (3): 186-191

DOI: https://doi.org/10.5114/pg.2017.70471

Key words: E-cadherin, colon cancer, colorectal cancer, aspartate aminotransferase, alanine aminotransferase.

Address for correspondence: Konrad Zaręba MD, $2^{\text {nd }}$ Department of General and Gastroenterological Surgery, Medical University of Bialystok, 24 a M. Skłodowskiej-Curie St, 15-276 Bialystok, Poland, phone: +48 857468 429, e-mail: konrad.zareba@umb.edu.pl

\begin{abstract}
Introduction: Colorectal cancer is the second most common cancer in terms of incidence in Poland. It is also the second most common cause of cancer deaths in men and the third women. In $75-80 \%$ of cases, depending on sources, it is of an occasional nature, and in the remaining $20-25 \%$ it has a hereditary character.

Aim: To compare the levels of E-cadherin in blood serum with some histopathological and clinical features. E-cadherin is an adhesion molecule, loss of function of which is suspected to influence both cancer progression and metastasis.

Material and methods: The study group comprised 48 patients diagnosed with colorectal cancer treated surgically in the Second Department of General and Gastroenterological Surgery, Medical University Hospital in Bialystok.

Results: As has been shown here, there is no statistically significant relationship between the levels of E-cadherin in blood serum and the possible prognosis to the progression of colorectal cancer. However, it was indicated that there appears to be a statistically significant relationship between blood serum E-cadherin levels and the levels of alanine aminotransferase and aspartate aminotransferase in patients with colorectal cancer.

Conclusions: The authors suggest that this significance may require further study.
\end{abstract}

\section{Introduction}

Colorectal cancer, also known as colon or bowel cancer, takes second place in Poland in terms of the number of new cases diagnosed every year [1]. It is also listed as the second and third cause of cancer deaths for men and women per year, respectively. In 75-80\% of cases, depending on source, the colorectal cancer has a self-contained character and in the remaining $20-25 \%$ the cause is hereditary [1-3].

The adhesion phenomenon plays a crucial role in the regulation of vital biological mechanisms on a single-cell level, such as growth, differentiation, and migration. The proteins involved in the process of cellular adhesion are the so-called cellular adhesion molecules (CAMs) $[4,5]$. These take part as a go-between in sideto-side relations of cells and between cells and extracellular matrix. There is strong evidence that inappropriate adhesion causes neoplastic cells to become invasive [6].
Cadherins are a large group of adhesion proteins, which, mostly by calcium ion binding in their structure, take part in cellular relations $[6,7]$. These transmembrane proteins are able to recognise other molecules of the same type and create junctions with them. Classical cadherins: N-cadherin, E-cadherin, and P-cadherin, build the so-called adherence junctions and are needed for proper functioning of cell-to-cell adhesion mechanisms. E-cadherin belongs to a super-family of adhesion molecules dependent on calcium ions [6]. It is suggested that functional disorders of this molecule lead to neoplastic growth $[6,7]$. On the other hand, the existence of metastases depends on E-cadherin's loss of function, what has already been proven [8]. These relations had been described in cases of prostate and lung cancer [9]. It is also suggested that E-cadherin disorders have a strong influence on the progression of neoplastic diseases of the stomach, pancreas, and the large intestine [10-12]. 
Aim

The goal of this study was to point out the correlations between blood serum levels of E-cadherin and clinical, anatomical, and histopathological staging of the disease in patients with colorectal cancer.

\section{Material and methods}

\section{The study group}

The study group comprised 48 patients diagnosed with colorectal cancer treated surgically in the Second Department of General and Gastroenterological Surgery, Medical University Hospital in Bialystok. In the study group there were 14 women and 34 men. Mean age was 67 years. In 28 cases the lesion was located in the colon, and in the rectum in 20 others. In 14 patients of the study group there were coexisting, confirmed liver metastases. In 45 cases the tumour had been described as a middle-stage histological grading (G2) and in the other three cases it was poorly differentiated (G3). Distribution of patients according to the TNM classification was as follows: stage I was diagnosed in 3 patients, II in the next 14, III was diagnosed in 18 patients, and IV in 13 patients. Table I shows the clinical characteristics of the patients in the study group.

Blood samples from patients with colorectal cancer were collected to clot before every surgery. Standard sample volume was 3-5 ml, which allowed to obtain up to $1.5 \mathrm{ml}$ of serum after clotting was completed. Clotting time was approximately $120 \mathrm{~min}$ at room temperature. Samples were left in a refrigerator for about 2-4 h for the clot to be fully formed. The samples were then transported to a laboratory, where centrifugation was performed at $3000 \mathrm{rpm}$ (rounds-per-minute) for $10 \mathrm{~min}$ at room temperature. After centrifugation, the serum was secured at $-80^{\circ} \mathrm{C}$ until assayed.

\section{The control group}

The control group consisted of 24 healthy subjects (13 men and 11 women, mean age of 60 years for women and 58 for men). Tests were carried out after obtaining the consent of the Bioethics Committee. Each of the patients received information on the method and purpose of research and gave written informed consent to participate in the research.

\section{Enzyme-linked immunoabsorbent assays (ELISA)}

E-cadherin concentrations were measured with a quantitative sandwich enzyme immunoassay (R\&D Systems, Abingdon, UK). Serum samples were incubated on microtitre plates pre-coated with a murine monoclonal antibody against E-cadherin. The platelets were washed, and an enzyme-linked polyclonal antibody (part of the ELISA kit) specific for E-cadherin was added to the wells. After the second washing procedure, a substrate solution was added. This substrate coloured in proportion to the amount of E-cadherin, which was bound to the microtitre plate. The samples were tested in duplicate and there were no statistically significant differences between assays. Human E-cadherin Quantikine Colorimetric Sandwich ELISA Kit by R\&D Systems recognised recombinant and natural human E-cadherin. The results are presented in nanograms per millilitre.

\section{Statistical analysis}

Statistical analysis was performed based on the program Statistica 8.0. The $U$ Mann-Whitney and Kruskal-Wallis tests were used for comparison of the two groups. Non-parametric Spearman's correlations were used to determine the relation between the level of E-cadherin, clinicopathological factors, and morphological parameters of blood. A $p$-value $<0.05$ was considered statistically significant.

\section{Results}

There were no statistically significant differences between the levels of E-cadherin in blood serum of patients with colorectal cancer and the control group, $p>0.05$. Magnitude control group values ranged from 51.2 to $85.1 \mathrm{ng} / \mathrm{ml}$ with an average of $61.4 \mathrm{ng} / \mathrm{ml}$, and the group of colorectal cancer ranged from 42.2 to

Table I. Clinical characteristics of the patients

\begin{tabular}{|c|c|c|c|c|c|c|c|c|}
\hline Parameter & & $N$ & Parameter & & $N$ & Parameter & & $N$ \\
\hline \multirow[t]{2}{*}{ Gender } & $F$ & 14 & T feature & $\mathrm{T} 1$ & 1 & M feature & MO & 30 \\
\hline & $M$ & 34 & & $\mathrm{~T} 2$ & 10 & & M1 & 14 \\
\hline \multirow[t]{2}{*}{ G feature } & $\mathrm{G} 2$ & 45 & & $\mathrm{~T} 3$ & 37 & TNM staging & I & 3 \\
\hline & G3 & 3 & $\mathrm{~N}$ feature & NO & 23 & & II & 14 \\
\hline \multirow{2}{*}{$\begin{array}{l}\text { Location of primary } \\
\text { tumour }\end{array}$} & Rectum & 20 & & N1 & 15 & & III & 18 \\
\hline & Colon & 28 & & N2 & 10 & & IV & 13 \\
\hline
\end{tabular}


Table II. A comparison of the E-cadherin between the study and control groups

\begin{tabular}{lcccccc} 
Group & $N$ & \multicolumn{3}{c}{ E-cadherin [ng/ml] } \\
\cline { 3 - 6 } & & Mean & Median & SD & Range \\
\hline Normal & 24 & 61.44 & 60 & 8.84 & $51.18-85.08$ \\
\hline Tumour & 48 & 61.71 & 58.51 & 12.75 & $45.22-110.26$
\end{tabular}

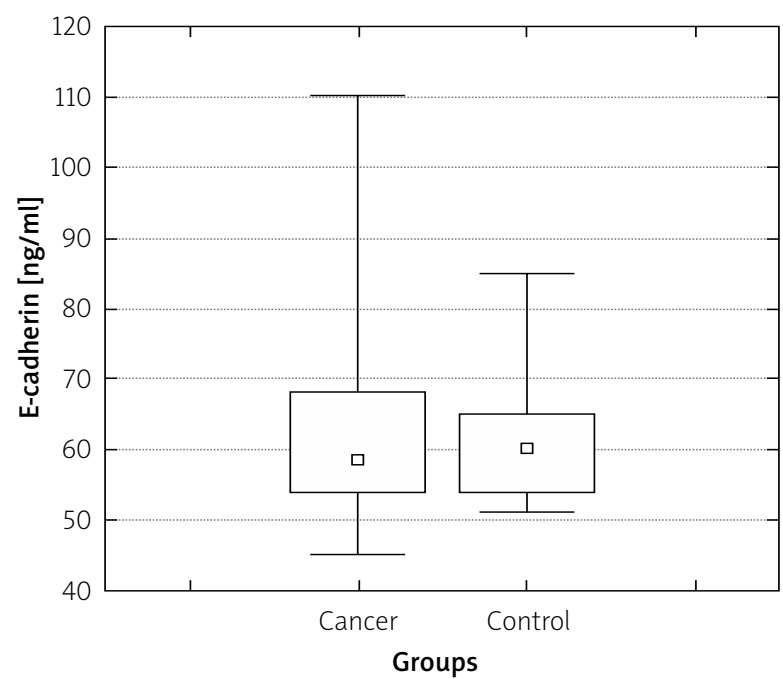

- Median $\square 25-75 \%$ I Min.-max.

Figure 1. A graphic representation of E-cadherin levels in the serum of patients with colorectal cancer in comparison with control groups

$110.3 \mathrm{ng} / \mathrm{ml}$, with an average of $61.7 \mathrm{ng} / \mathrm{ml}$. The following relation is hereby shown in Table II and the graphic representation is in Figure 1.

There were also no significant correlations between the levels of E-cadherin in blood serum of patients with colorectal cancer and the level of malignancy in histopathological changes, $p>0.05$, as shown in Table III.

There were also no statistically significant differences in the levels of blood serum E-cadherin and tumour stage (Table IV), the occurrence of lymph node metastasis (Table V), or liver metastases (Table VI).

The results of the concentration levels of blood serum E-cadherin were also correlated with such characteristics as age, the assessment of biochemical parameters (haematocrit, haemoglobin concentration, WBC, RBC, PLT), prothrombin time, prothrombin index, international normalise ratio (INR), total protein, albumin, and liver enzymes: alanine aminotransferase (ALT), aspartate aminotransferase (AST). The results of these comparisons are shown in Table VII. The nonparametric Spearman correlations were used to assess the statistical relationships.

Statistically significant correlation was observed between the level of E-cadherin and the ALT ( $p=0.044)$ and AST ( $p=0.006)$ levels in the blood serum of these patients. Graphic representations of these relationships are shown in Figures 2 and 3.

\section{Discussion}

Disorders of E-cadherin expression are currently a subject being raised by many authors, considering

Table III. Comparing the levels of E-cadherin in blood serum of patients with colorectal cancer and the degree of malignancy of histopathological changes

\begin{tabular}{cccccccc} 
G & $\boldsymbol{N}$ & Mean & $\begin{array}{c}\text { Standard } \\
\text { deviation }\end{array}$ & Minimum & Median & Maximum & $P$-value \\
\hline 2 & 42 & 0.459 & 0.145 & 0.271 & 0.417 & 0.971 & 0.460 \\
\cline { 1 - 5 } 3 & 6 & 0.381 & 0.083 & 0.288 & 0.411 & 0.445 &
\end{tabular}

Table IV. Comparing the levels of E-cadherin in blood serum of patients with colorectal cancer and the staging of the tumour (Mann-Whitney test)

\begin{tabular}{cccccccc} 
pT & $\boldsymbol{N}$ & Mean & $\begin{array}{c}\text { Standard } \\
\text { deviation }\end{array}$ & Minimum & Median & Maximum \\
\hline 1 & 1 & 0.398 & & 0.398 & 0.398 & 0.398 \\
\hline 2 & 8 & 0.389 & 0.116 & 0.316 & 0.328 & 0.523 \\
\hline 3 & 39 & 0.459 & 0.146 & 0.271 & 0.417 & 0.971
\end{tabular}


Table V. Comparing the level of E-cadherin in blood serum of patients with colorectal cancer and the occurrence of metastases to the lymph nodes (Kruskal-Wallis test)

\begin{tabular}{cccccccc} 
pN & $\boldsymbol{N}$ & Mean & $\begin{array}{c}\text { Standard } \\
\text { deviation }\end{array}$ & Minimum & Median & Maximum & $P$-value \\
\hline 0 & 23 & 0.456 & 0.161 & 0.288 & 0.412 & 0.971 & 0.895 \\
\cline { 1 - 5 } & 15 & 0.459 & 0.134 & 0.271 & 0.463 & 0.695 \\
\hline 2 & 10 & 0.430 & 0.106 & 0.288 & 0.416 & 0.661
\end{tabular}

Table VI. Comparing the level of E-cadherin in blood serum of patients with colorectal cancer and the occurrence of liver metastases (Mann-Whitney test)

\begin{tabular}{cccccccc} 
pM & $\boldsymbol{N}$ & Mean & $\begin{array}{c}\text { Standard } \\
\text { deviation }\end{array}$ & Minimum & Median & Maximum & $P$-value \\
\hline 0 & 34 & 0.452 & 0.144 & 0.271 & 0.417 & 0.971 & 0.939 \\
\hline 1 & 14 & 0.450 & 0.133 & 0.288 & 0.399 & 0.695 &
\end{tabular}

Table VII. Correlation between E-cadherin levels in the blood serum of the patients and age, and the results of the assessment of biochemical parameters

\begin{tabular}{lcc} 
Parameter & $\boldsymbol{R}$ & $\boldsymbol{P}$-value \\
\hline Age [years] & 0.23 & 0.110 \\
\hline $\mathrm{Ht}(\%)$ & 0.14 & 0.413 \\
\hline $\mathrm{Hb}[\mathrm{g} / \mathrm{dl}]$ & 0.24 & 0.164 \\
\hline WBC $\left[10^{3} / \mu \mathrm{l}\right]$ & 0.11 & 0.542 \\
\hline PLT $\left[10^{3} / \mu \mathrm{ll}\right]$ & -0.25 & 0.141 \\
\hline RBC $\left[10^{6} / \mu \mathrm{l}\right]$ & -0.03 & 0.850 \\
\hline Prothrombin time $[\mathrm{s}]$ & 0.19 & 0.285 \\
\hline Prothrombin index $(\%)$ & -0.11 & 0.547 \\
\hline INR & 0.21 & 0.218 \\
\hline Total protein $[\mathrm{g} / \mathrm{dl}]$ & 0.06 & 0.802 \\
\hline Albumins $(\%)$ & 0.03 & 0.882 \\
\hline AST $[\mathrm{IU}]$ & 0.53 & 0.006 \\
\hline ALT $[$ IUU & 0.40 & 0.044
\end{tabular}

both colorectal cancer and lung cancer, as well as gastric cancer and cancers of the thyroid. Many note the decrease in expression of E-cadherin in the course of colorectal cancer, which is associated with a decrease of its expression in the cell membrane [10-12]. However, in some cases we also have to deal with its overexpression, which is related to its accumulation in the cytoplasm and a decrease of E-cadherin at the cellular membrane $[13,14]$. Most previous studies on the level of expression of E-cadherin were carried out within the primary tumour, weather further examination of the

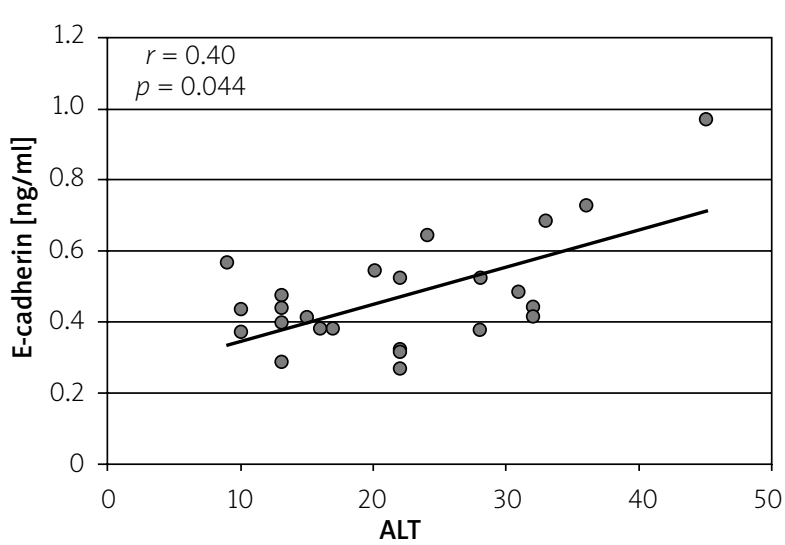

Figure 2. The relationship between the level of E-cadherin and serum alanine aminotransferase (ALT) values

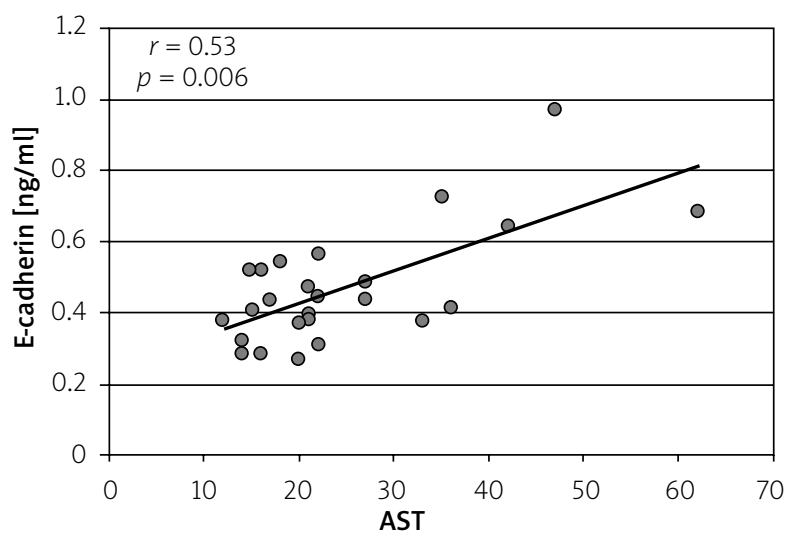

Figure 3. The relationship between the level of $\mathrm{E}$-cadherin in the serum and the value of aspartate aminotransferase (AST) 
expression of E-cadherin was assessed in metastatic lymph nodes or in the secondary changes in the liver [12-15]. Based on these studies a thesis was established that the decrease in the expression of E-cadherin in the primary tumour is associated with its ability to spread, and it can be a prognostic factor for the further course of cancer. Some researchers also suggest that the decrease in the expression of E-cadherin is associated with low histological differentiation of the tumour. It has been shown that in the case of a metastatic lesion, the level of expression of E-cadherin is significantly higher than in the primary tumour. In lymph node metastases the level was higher by about 40\%, and for changes in the liver by $45 \%$ compared to the primary tumour. This may suggest that cancer cells after the occupation of a lymph node or liver acquire the ability to elevated expression of E-cadherin, which allows them to further develop.

These observations were confirmed only among patients who underwent surgical treatment, where the level of E-cadherin was determined in tissues removed [13-15]. In the above work the authors focus on another aspect related to the level of expression of E-cadherin, associated with the designated E-cadherin levels in serum of patients with colorectal cancer. This study could be important in detecting colorectal cancer and eventually in the evaluation of treatment efficacy. However, there was no difference in the level of E-cadherin expression between the test and the control group. This precludes the use of E-cadherin levels in blood serum as a potential tumour marker.

An analysis was also carried out, taking into consideration the relationship between the levels of E-cadherin and the primary tumour histopathological features, the presence of lymph node metastasis, and distant metastases to the liver. There were no significant relations that would indicate that the level of expression of E-cadherin may be predictive as to the exponent of the disease. Also, patient age did not affect the test result.

The authors observed the relationship between the level of expression of E-cadherin in blood serum and the ALT and AST levels. It may be associated with functional damage to the liver, but there arises another thesis that a similar correlation should exist in the case of metastases to the liver, and this has not been demonstrated.

To sum up, the level of expression of E-cadherin determined in the primary tumour and eventual metastatic lesions might be a relevant factor to a possible outcome, it can also lead to further research into improving the treatment. In contrast, the level of expression of E-cadherin in blood serum of patients with colorectal cancer at present has no diagnostic significance.
As for the correlations between serum E-cadherin levels and the levels of ALT and AST, as shown in this observation, they require further study.

\section{Conclusions}

Determination of the level of expression of E-cadherin in the serum of patients with colorectal cancer to date shows no clinical significance. The relationship between the levels of blood serum expression of E-cadherin and the levels of AST and ALT in patients with colorectal cancer requires further study.

\section{Conflict of interest}

The authors declare no conflict of interest.

\section{References}

1. Didkowska J, Wojciechowska U, Zatoński W. Cancer in Poland in 2009. Centrum Onkologii - Instytut im. Marii Skłodowskiej-Curie, Warsaw 2011.

2. Łacko A. Colorectal cancer. Post Nauk Med 2011; 24: 137-45.

3. Ahmed RL, Schmitz KH, Anderson KE, et al. The metabolic syndrome and risk of incident colorectal cancer. Cancer 2006; 107: 28-36.

4. Mantur M, Wojszel J. Cząsteczki adhezyjne oraz ich udział w procesie zapalnym i nowotworowym. Pol Merk Lek 2008; 24: $177-80$

5. Tsanou E, Peschos D, Batistatou A, et al. The E-cadherin adhesion molecule and colorectal cancer. A global literature approach. Anticancer Res 2008; 28 (6A): 3815-26.

6. Kwiatkowski P, Godlewski J, Śliwińska-Jewsiewicka A, et al. Cell adhesion molecules in the process of carcinogenesis and metastasis. Pol Ann Med 2009; 16: 128-37.

7. Paschos KA, Canovas D, Bird NC. The role of cell adhesion molecules in the progression of colorectal cancer and the development of liver metastasis. Cell Signal 2009; 21: 665-74.

8. Kouso H, Yano T, Maruyama R, et al. Differences in the expression of epithelial-mesenchymal transition related molecules between primary tumors and pulmonary metastatic tumors in colorectal cancer. Surg Today 2013; 43: 73-80.

9. Soyama A, Eguchi S, Takatsuki M, et al. Significance of the serum level of soluble E-cadherin in patients with HCC. Hepatogastroenterology 2008; 55: 1390-3.

10. Inge LJ, Barwe SP, D’Ambrosio J, et al. Soluble E-cadherin promotes cell survival by activating epidermal growth factor receptor. Exp Cell Res 2011; 317: 838-48.

11. Lu MH, Huang CC, Pan MR, et al. Prospero homeobox 1 promotes epithelial-mesenchymal transition in colon cancer cells by inhibiting E-cadherin via miR-9. Clin Cancer Res 2012; 18: 6416-25.

12. Dorudi S, Hanby AM, Poulsom R, et al. Level of expression of E-cadherin mRNA in colorectal cancer correlates with clinical outcome. Br J Cancer 1995; 71: 614-6.

13. Hardy RG, Tselepis C, Hoyland J, et al. Aberrant P-cadherin expression is an early event in hyperplastic and dysplastic transformation in the colon. Gut 2002; 50: 513-9. 
14. Weiss JV, Klein-Scory S, Kübler S, et al. Soluble E-cadherin as a serum biomarker candidate: elevated levels in patients with late-stage colorectal carcinoma and FAP. Int J Cancer 2011; 128: 1384-92.

15. Okugawa Y, Toiyama Y, Inoue Y, et al. Clinical significance of serum soluble E-cadherin in colorectal carcinoma. J Surg Res 2012; 175: e67-73.

Received: 2.04 .2015

Accepted: 29.02.2016 